\title{
Aubusson, Néoux, Moutier-Rozelle, Saint-Alpinien, Saint-Pardoux-le-Neuf
}

\author{
Gilles Le Hello
}

\section{(2) OpenEdition \\ Journals}

Édition électronique

URL : http://journals.openedition.org/adlfi/5073

ISSN : 2114-0502

Éditeur

Ministère de la culture

Référence électronique

Gilles Le Hello, « Aubusson, Néoux, Moutier-Rozelle, Saint-Alpinien, Saint-Pardoux-le-Neuf », ADLFI.

Archéologie de la France - Informations [En ligne], Limousin, mis en ligne le 01 mars 2006, consulté le 19 avril 2019. URL : http://journals.openedition.org/adlfi/5073

Ce document a été généré automatiquement le 19 avril 2019

(C) Ministère de la Culture et de la Communication, CNRS 


\title{
Aubusson, Néoux, Moutier-Rozelle, Saint-Alpinien, Saint-Pardoux-le- Neuf
}

\author{
Gilles Le Hello
}

Identifiant de l'opération archéologique : 2662

Date de l'opération : 2006 (PI)

1 Le temps fort de l'année 2006 aura été le sondage sur le site du Pauquet à MoutierRozeille, site daté du Néolithique moyen et d'une grande homogénéité.

Deux autres thèmes déjà traités au coup par coup lors des années précédentes ont fait l'objet de recherches plus étendues : les mottes castrales et la frontière naturelle gauloise présumée entre Arvernes et Lémovices sur notre secteur de prospection, prolongée vers le sud-est.

\section{Les mottes castrales}

4 Deux nouveaux emplacements ont pu être repérés : le premier au hameau du Martineix dans la commune de Moutier-Rozeille où la motte constitue la sœur jumelle de celle signalée en 2005. Elle encadre un itinéraire ancien nord-sud et verrouille, avec trois autres déjà signalées, deux passages dans les gorges de la rivière Rozeille, rive droite et rive gauche. Le second se situe sur un cheminement antique également nord-sud de Felletin à Bellegarde-en-Marche, à l'est du village du Quioudeneix, dans la commune de Néoux.

5 Le manque d'archives ne nous permet malheureusement pas d'en savoir plus à leur sujet.

\section{La frontière gauloise}

7 Nous avons repris les recherches effectuées en 2005 sur les quatre communes de SaintAvit-de-Tardes, Néoux, Saint-Pardoux-le-Neuf et Saint-Alpinien en les étendant de $20 \mathrm{~km}$ vers le sud-est, aux sources des rivières Rozeille et Tardes, sur la ligne de partage des eaux. 
8 Enfin, nous avons terminé la reconnaissance de la voie gallo-romaine secondaire de Néoux à Aubusson dans les communes de Saint-Pardoux-le-Neuf et Aubusson.

$9 \quad$ Le Hello Gilles

INDEX

Index chronologique : Empire romain, Moyen Âge, Néolithique moyen

peuple Arverne, Lémovices

operation Prospection inventaire (PI), Prospection diachronique (PRD)

Index géographique : Limousin, Creuse (23), Aubusson

Thèmes : frontière, itinéraire, motte, passage, rivière, route, voie romaine

\section{AUTEURS}

GILLES LE HELLO

Bénévole 